\title{
It's Not a Spider Bite, It's Community-Acquired Methicillin-Resistant Staphylococcus aureus
}

\author{
Tamara J. Dominguez, MD
}

Skin and soft tissue infections caused by hospitalacquired methicillin-resistant Staphylococcus aureus, or HA-MRSA, have been a problem in hospital and nursing home settings for several years. ${ }^{1}$ In recent years, infections caused by a new isolate termed community-acquired MRSA (CA-MRSA) have been increasing in incidence, ${ }^{2-4}$ and outbreaks of CA-MRSA have been identified in other settings, including athletic teams and prisons. ${ }^{5-7}$ Community-acquired MRSA differs from HA-MRSA in that CA-MRSA is not multidrug-resistant and can usually be treated with clindamycin, trimethoprim/ sulfamethoxazole, or linezolid. ${ }^{8,9}$ Both organisms carry the staphylococcal cassette chromosome mec $A$ (SCCmec $A$ ) gene that encodes resistance to the $\beta$-lactams ${ }^{10,11}$ - the class of antibiotics most commonly used in treating skin and soft tissue infections. At this time, it is not known whether CAMRSA is the result of HA-MRSA that escaped the hospital setting and mutated to its present form or is community-generated in origin..$^{12}$ Several studies are currently being conducted in molecular genetics to identify the source of CA-MRSA and effectively treat it. ${ }^{13}$ This article presents a case review of several CA-MRSA infections identified in a community clinic setting, identifies clues that might lead the clinician to suspect a CA-MRSA infection, recommends questions to consider in making this diagnosis, and discusses options for treatment. It may be that contact with prisons or prisoners needs to be placed on the list of known risk factors associated with CA-MRSA.

Submitted, revised, 20 October 2003.

From the Bishop Ernest T. Dixon Clinic, Methodist Healthcare Ministries of South Texas, Inc., San Antonio. Address correspondence to Tamara J. Dominguez, MD, Bishop Ernest T. Dixon Jr. Clinic, 1954 East Houston Street \#201, San Antonio, TX 78202.

This work was supported by Methodist Healthcare Ministries of South Texas, Inc., which operates the Dixon Clinic.

\section{Case Review}

From July 2002 to September 2003, 10 patients were identified as having CA-MRSA skin and soft tissue infections at an indigent health care clinic in San Antonio, Texas. These infections were classified as community-acquired MRSA based on several factors: (1) none of the patients had risk factors for nosocomially acquired MRSA (ie, recent hospitalization or surgery ${ }^{1}$ ) or those risk factors previously associated with acquisition of MRSA outside a short-term care setting: residence in a long-term care facility, current intravenous drug abuse, or underlying illnesses such as cardiovascular or pulmonary disease, diabetes mellitus, malignancy, or chronic skin disease such as eczema,,${ }^{14}$ and (2) antimicrobial resistance patterns were consistent with CA-MRSA-ie, they showed susceptibility to several classes of antimicrobial agents other than $\beta$-lactams.

Patients were identified through a positive wound culture using an aerobic/anaerobic Culturette. Many had been diagnosed and treated for other causes of their infection, including spider bites, impetigo, and varicella zoster. Four of the patients had been incarcerated and reported they had been treated for recurring skin infections several times while in prison. One of these 4 patients had a positive nasal culture for CA-MRSA. The other 6 patients had contact with either a prison facility or someone recently released from prison. One patient also played on his high school football team. Several patients were treated by other providers for what were thought to be spider bites. All CA-MRSA infections treated at the community clinic responded well to clindamycin, mupirocin, and drainage of the abscess, if present. The sensitivity pattern was similar in the positive MRSA cultures in that all were sensitive to clindamycin, rifampin, trimethoprim/sulfamethoxazole, and vancomycin (Table 1). All the isolates were resistant to amoxicillin/clavulanic acid, cefazolin, erythromy- 


\begin{tabular}{|c|c|c|c|c|c|c|c|c|c|c|c|}
\hline \multirow[b]{2}{*}{ Antimicrobial Agent } & \multirow[b]{2}{*}{$\mathrm{MIC}^{*}$} & \multicolumn{10}{|c|}{ Cases } \\
\hline & & A & B & $\mathrm{C}$ & $\mathrm{D}$ & $\mathrm{E}$ & $\mathrm{F}$ & G & $\mathrm{H}$ & I & $\mathrm{J}$ \\
\hline Amoxicillin/clavulanate & $\geq 8 / 4$ & $\mathrm{R}$ & $\mathrm{R}$ & $\mathrm{R}$ & $\mathrm{R}$ & $\mathrm{R}$ & $\mathrm{R}$ & $\mathrm{R}$ & $\mathrm{R}$ & $\mathrm{R}$ & $\mathrm{R}$ \\
\hline Ampicillin/sulbactam & $\geq 32$ & $\mathrm{R}$ & $\mathrm{R}$ & - & $\mathrm{R}$ & $\mathrm{R}$ & $\mathrm{R}$ & - & $\mathrm{R}$ & $\mathrm{R}$ & $\mathrm{R}$ \\
\hline Cefazolin & $\geq 32$ & $\mathrm{R}$ & $\mathrm{R}$ & - & $\mathrm{R}$ & $\mathrm{R}$ & $\mathrm{R}$ & $\mathrm{R}$ & $\mathrm{R}$ & $\mathrm{R}$ & $\mathrm{R}$ \\
\hline Ciprofloxacin & $\leq 0.5 / \geq 4$ & $\mathrm{~S}$ & $\mathrm{~S}$ & - & $S$ & $\mathrm{~S}$ & $\mathrm{~S}$ & S & $\mathrm{R}$ & $\mathrm{R}$ & $\mathrm{R}$ \\
\hline Clindamycin & $\leq 8$ & $\mathrm{~S}$ & $\mathrm{~S}$ & $\mathrm{~S}$ & S & $\mathrm{S}$ & $\mathrm{S}$ & S & S & $\mathrm{S}$ & $\mathrm{S}$ \\
\hline Erythromycin & $\geq 8$ & $\mathrm{R}$ & $\mathrm{R}$ & $\mathrm{R}$ & $\mathrm{R}$ & $\mathrm{R}$ & $\mathrm{R}$ & $\mathrm{R}$ & $\mathrm{R}$ & $\mathrm{R}$ & $\mathrm{R}$ \\
\hline Gentamycin & $\leq 2$ & - & - & - & - & - & $\mathrm{S}$ & - & - & - & $\mathrm{S}$ \\
\hline Levofloxacin & $\leq 1 /=4$ & $\mathrm{~S}$ & $\mathrm{~S}$ & - & S & $\mathrm{S}$ & $\mathrm{S}$ & - & I & I & I \\
\hline Nitrofurantoin & $\leq 32$ & $\mathrm{~S}$ & $\mathrm{~S}$ & - & S & $\mathrm{S}$ & $\mathrm{S}$ & - & - & $\mathrm{S}$ & - \\
\hline Oxacillin & $\geq 8$ & $\mathrm{R}$ & $\mathrm{R}$ & $\mathrm{R}$ & $\mathrm{R}$ & $\mathrm{R}$ & $\mathrm{R}$ & $\mathrm{R}$ & $\mathrm{R}$ & $\mathrm{R}$ & $\mathrm{R}$ \\
\hline Penicillin & $\geq 16$ & $\mathrm{R}$ & $\mathrm{R}$ & $\mathrm{R}$ & $\mathrm{R}$ & $\mathrm{R}$ & $\mathrm{R}$ & $\mathrm{R}$ & $\mathrm{R}$ & $\mathrm{R}$ & $\mathrm{R}$ \\
\hline Rifampin & $\leq 1$ & $\mathrm{~S}$ & $\mathrm{~S}$ & - & S & $\mathrm{S}$ & $\mathrm{S}$ & - & S & $\mathrm{S}$ & $\mathrm{S}$ \\
\hline Tetracycline & $\leq 1$ & $\mathrm{~S}$ & $\mathrm{~S}$ & - & S & $\mathrm{S}$ & $\mathrm{S}$ & - & S & $\mathrm{S}$ & - \\
\hline Trimethoprim/sulfa & $\leq 10$ & $\mathrm{~S}$ & $\mathrm{~S}$ & - & S & $\mathrm{S}$ & $\mathrm{S}$ & S & S & $\mathrm{S}$ & $\mathrm{S}$ \\
\hline Vancomycin & $\leq 0.5$ & $\mathrm{~S}$ & $\mathrm{~S}$ & S & S & $\mathrm{S}$ & $\mathrm{S}$ & S & S & $\mathrm{S}$ & $\mathrm{S}$ \\
\hline
\end{tabular}

${ }^{*}$ MIC, minimal inhibitory concentration; R, resistant; S, sensitive; I, intermediate; -, not reported.

cin, oxacillin, and penicillin. A brief detail of the patients' histories is outlined below (Table 2):

\section{Case A}

A 10-year-old girl was brought to the clinic by her mother for a lesion to her left lower extremity that the family thought was caused by a spider bite. She had been treated for impetigo at her pediatrician's office 2 weeks before, but her condition did not improve after treatment with amoxicillin/clavulanic acid. The patient was then seen at this community clinic, and her wound culture was positive for CAMRSA. Both the patient and her mother had recently visited the patient's father in prison. Her mother had been treated 2 weeks earlier for a similar infection and was told by the emergency department physician that her infection was the result of a spider bite. The patient's infection cleared after treatment with oral clindamycin and topical mupirocin applied to the wound.

\section{Case B}

A 24-year-old man presented to the clinic with a 4-day history of painful raised pustules to his left hip that the patient attributed to spider bites. A culture of these lesions proved positive for CAMRSA. The lesions cleared after treatment with oral clindamycin and topical mupirocin. His girlfriend had been treated at our clinic for a similar infection 4 months earlier but a culture was not done at that time. His girlfriend's sister had been hospitalized for an abscess on her abdomen caused by a "spider bite" during that same period. His girlfriend's other roommate was released from prison and had moved in with the patient's girlfriend and her sister 2 weeks before their infections began.

\section{Case C}

A 43-year-old man recently released from prison was treated at the clinic for multiple pustules over his legs, arms, and inguinal area. An aerobic/anaerobic wound culture was taken and was positive for CA-MRSA. This patient had been treated several times while in prison for similar lesions and was told they were the result of spider bites. His last intravenous drug use was 4 years before. This infection resolved after treatment with oral clindamycin and topical mupirocin.

\section{Case $D$}

A 25 -year-old woman was first treated in the emergency department for varicella zoster then at the clinic for impetigo that did not respond to amoxicillin/clavulanic acid or gatifloxacin. The patient developed an abscess on her right gluteal area with a central eschar. An aerobic/anaerobic culture was positive for CA-MRSA. The patient's boyfriend had recently been released from prison. The patient responded well to drainage of the abscess and 


\begin{tabular}{|c|c|c|}
\hline Patient & Patient's History & Association with Prison \\
\hline $\mathrm{A}$ & $\begin{array}{l}\text { 10-year-old girl treated for 'spider bite' to left } \\
\text { lower extremity. }\end{array}$ & $\begin{array}{l}\text { Had visited her father in prison and her mother had } \\
\text { been treated for 'spider bite' on her left elbow } 2 \\
\text { weeks prior. }\end{array}$ \\
\hline $\mathrm{B}$ & $\begin{array}{l}\text { 24-year-old man presented to clinic with complaint } \\
\text { of single 'spider bite' lesion to left hip. }\end{array}$ & $\begin{array}{l}\text { Girlfriend and girlfriend's sister both treated for 'spider } \\
\text { bites,' girlfriend's other roommate recently released } \\
\text { from prison. }\end{array}$ \\
\hline $\mathrm{C}$ & $\begin{array}{l}\text { 43-year-old man with multiple pustules to legs, } \\
\text { arms, and inguinal area. }\end{array}$ & $\begin{array}{l}\text { Recently released from prison. While in prison, he was } \\
\text { treated several times for similar infections. }\end{array}$ \\
\hline $\mathrm{D}$ & $\begin{array}{l}\text { 25-year-old woman diagnosed with varicella zoster } \\
\text { and then impetigo. Developed abscess with } \\
\text { central eschar on right gluteus. }\end{array}$ & Boyfriend recently released from prison. \\
\hline $\mathrm{E}$ & $\begin{array}{l}\text { 45-year-old woman, mother of case D. Treated for } \\
\text { left gluteal abscess } 1 \text { week after her daughter, }\end{array}$ & See above. \\
\hline $\mathrm{F}$ & $\begin{array}{l}\text { 41-year-old man with recurring skin infections } \\
\text { thought to be impetigo. }\end{array}$ & $\begin{array}{l}\text { Recently released from prison. Treated several times } \\
\text { while in prison for similar lesions. }\end{array}$ \\
\hline G & $\begin{array}{l}\text { 50-year-old man with multiple furuncles on his } \\
\text { legs and arms. Failed treatment with } \\
\text { ciprofloxacin for what was thought to be } \\
\text { impetigo. }\end{array}$ & $\begin{array}{l}\text { Recently released from prison. While in prison, he had } \\
\text { a history of recurring 'staph' infections. }\end{array}$ \\
\hline $\mathrm{H}$ & $\begin{array}{l}\text { 36-year-old woman with multiple furuncles to } \\
\text { knee, posterior neck, and scalp. Abscess to left } \\
\text { gluteus. }\end{array}$ & $\begin{array}{l}\text { Visited her pregnant daughter in prison for several } \\
\text { weeks before her outbreak. }\end{array}$ \\
\hline I & $\begin{array}{l}\text { 16-year-old man with single boil to right axilla. } \\
\text { Was treated for a 'spider bite' on his neck } 1 \\
\text { year before. }\end{array}$ & $\begin{array}{l}\text { Father released from prison and returned home } 1 \text { week } \\
\text { prior. Father reported being treated twice for 'spider } \\
\text { bites' while incarcerated. }\end{array}$ \\
\hline $\mathrm{J}$ & $\begin{array}{l}\text { 42-year-old man with single 'spider bite' to his left } \\
\text { groin. Had been treated for recurring skin } \\
\text { infections several times since release from prison } \\
8 \text { years ago. Was treated for his first skin lesion } \\
\text { while in prison. }\end{array}$ & $\begin{array}{l}\text { Incarcerated } 8 \text { years prior. Sister and niece also treated } \\
\text { for 'spider bites' during previous year. }\end{array}$ \\
\hline
\end{tabular}

was treated with oral clindamycin and topical mupirocin.

\section{Case $E$}

Case D's 45-year-old mother presented at the clinic 1 week after her daughter's treatment for a left gluteal abscess. The wound culture proved positive for CA-MRSA. This infection cleared with incision and drainage of the abscess and antimicrobial treatment with clindamycin and mupirocin.

\section{Case F}

A 41-year-old man recently released from prison presented to the clinic with a history of recurring skin infections thought to be impetigo. He had been treated several times while in prison for similar lesions. The wound culture and nasal swab done at clinic were positive for CA-MRSA. The patient's lesions cleared after treatment with oral clindamycin. Mupirocin was applied intranasally and topically to his wounds.

\section{Case G}

A 50-year-old man presented to the clinic with multiple furuncles on his legs and arms. He had been recently released from prison and had a history of recurring "staph" infections while in prison. This patient failed treatment with ciprofloxacin for what was thought to be impetigo. His wound culture done at clinic was positive for CA-MRSA. The lesions resolved after treatment with clindamycin and mupirocin.

\section{Case $\mathrm{H}$}

A 36-year-old woman was treated at the clinic for multiple furuncles to the left knee, nape of the neck, and scalp. This patient also had an abscess on her left gluteus that was incised and drained. Wound cultures done on all areas proved positive for CA-MRSA. The patient had been visiting her pregnant daughter in prison for several weeks before her outbreak. This infection cleared after drainage of her abscess and treatment with clindamycin and mupirocin. 


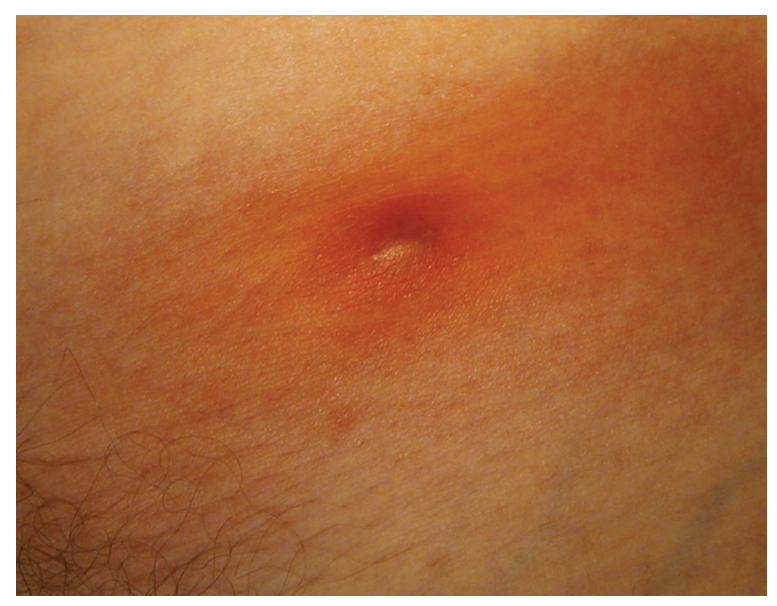

Figure 1. CA-MRSA lesion of patient J. Location: left groin.

\section{Case I}

A 16-year-old boy presented to the clinic with a 4-day history of a "boil" to his right axilla. The patient stated he had a similar infection on his neck a year before and was told it was from a "spider bite" when he sought medical attention. Cultures taken from his axilla grew CA-MRSA and a Gram stain showed many Gram-positive cocci. It is notable that the patient's father had been recently released from prison and returned home 1 week before the patient's most recent infection. The father reported being treated twice while incarcerated for similar lesions. The patient participated in high school football and was not aware that anyone else on the team had experienced a similar infection.

\section{Case J}

A 42-year-old man presented to the clinic with a 3-day history of a "spider bite" to his left inguinal area. (Figures 1-3). He had been treated several times over an 8-year period for similar lesions and was told each time it was the result of a spider bite. His first episode occurred when he was incarcerated in the county jail. The patient stated that his sister and niece were both treated for similar "spider bites." The patient's wound culture was positive for MRSA and responded well to treatment with clindamycin.

\section{Discussion}

These cases demonstrate the ease with which patients and clinicians can confuse CA-MRSA infections with other soft tissue infections. The diagno-

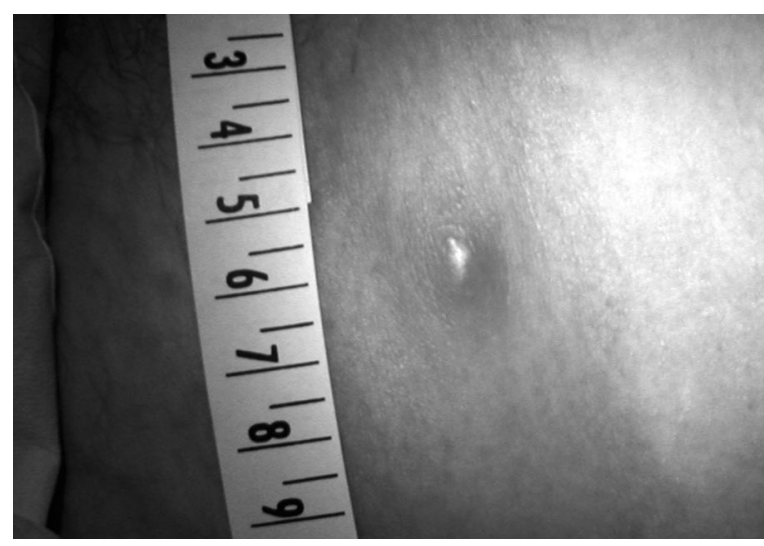

Figure 2. Lesion of patient $\mathrm{J}$.

sis of spider bites has been noted in other investigations of CA-MRSA outbreaks. ${ }^{5}$ It is not known why CA-MRSA infections are commonly misdiagnosed as spider bites. In several of the above cases, a spider bite was a common diagnosis for those CA-MRSA infections that presented as solitary lesions. One of the patients at the clinic (case D) developed an abscess with a central eschar, similar in appearance to the bite of a brown recluse spider (Loxosceles reclusa). Both the patient and her physician (the author) had at first attributed her infection to a brown recluse spider bite, based solely on the appearance of her lesion. This was not the first time this misdiagnosis has been made as other skin lesions have been wrongly attributed to the brown recluse spider in other disease processes such as Lyme disease, ${ }^{15}$ at times in areas outside the endemic range of the brown recluse. ${ }^{16}$ It was not until the patient's wound culture showed CAMRSA that the correct diagnosis was made.

During the interviewing process several other points were noted. First, those patients who were incarcerated (cases C, F, G, J) and former prisoners who had contact with the case study patients (cases A, B, D, E, H, I) had been incarcerated at different correctional facilities. This leads us to question the prevalence of CA-MRSA infections in prisons. Skin and soft tissue infections have been recognized problems in correctional facilities ${ }^{6}$; until recently, however, CA-MRSA outbreaks have been reported in only 2 prisons-one in Los Angeles County, California, ${ }^{5}$ and the other in Mississippi. ${ }^{6}$ Second, all patients who had been incarcerated reported that their first outbreak of skin infections started after being sent to prison. Finally, some patients at the clinic reported or were noted to have large, firm 


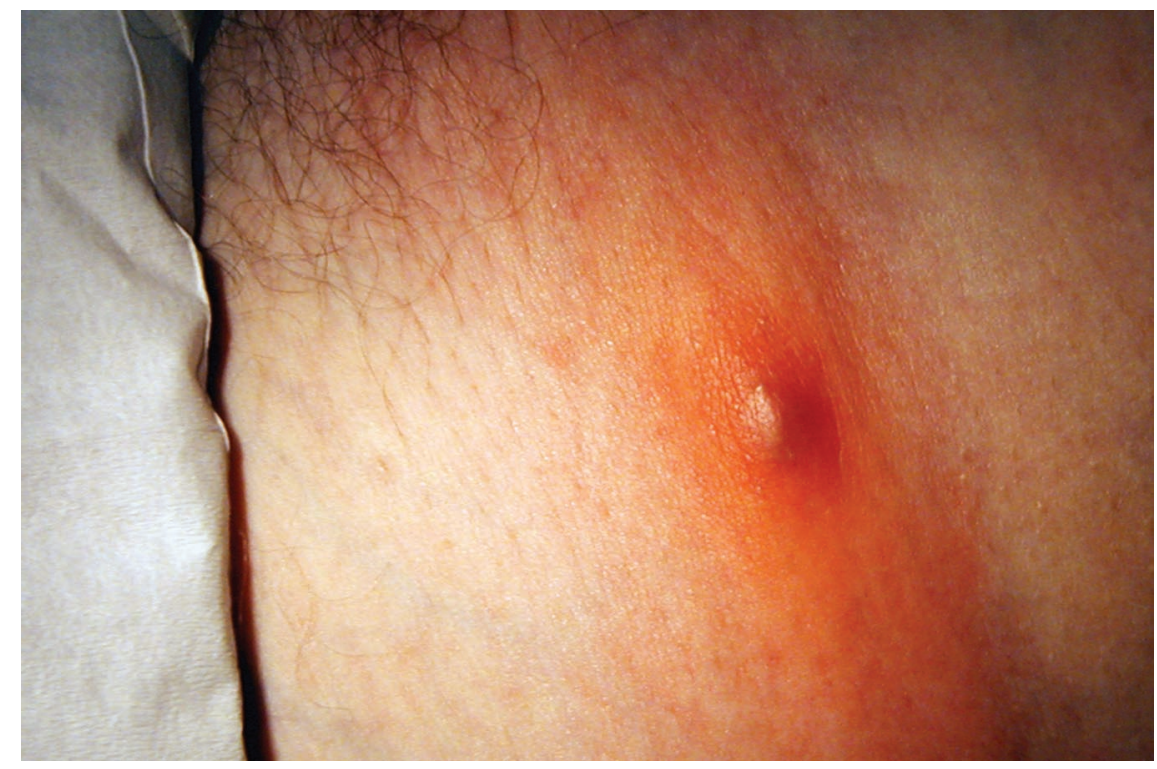

Figure 3. CA-MRSA lesion of patient J. Location: left groin.

pustules with a central hard white core, similar to furunculosis. Several patients stated that selfremoval of this core resulted in clearing of their infection.

Obtaining the proper diagnosis of a CA-MRSA infection is important because misdiagnosis and delay of proper treatment can have serious consequences for both the patient and the medical community. An improperly treated CA-MRSA infection results in increased medical costs for the patient and community resulting from multiple office and emergency department visits and possibility of hospitalization. In addition, the risk of transferring the infection increases as the number of contacts, especially familial, increases. Community-acquired MRSA infections with secondary familial transmission have been described in other reports. ${ }^{17}$ Although skin and soft tissues is the most common reported site of infection, CA-MRSA has been noted in invasive diseases such as bacteremia, endocarditis, osteomyelitis, and pneumonia. ${ }^{5,9}$ In 1999, 4 pediatric deaths in Minnesota and North Dakota were attributed to CA-MRSA. ${ }^{18}$ None of the 4 children had established risk factors for MRSA infection (ie, prolonged hospitalization, invasive or surgical procedures, indwelling catheters, endotracheal tubes, and prolonged or recurrent exposure to antibiotics). ${ }^{2}$ All 4 pediatric cases described above were initially treated with a cephalosporin antibiotic to which the organism was resistant. The delayed use of the correct antibiotic may have contributed to their deaths. At this time, it is unclear how common CA-MRSA infections occur within the adult or pediatric community, although they are being reported in increasing numbers. ${ }^{3}$ The CDC is currently conducting surveillance for CA-MRSA in selected regions of the country to determine the incidence and risk factors for MRSA in the community. ${ }^{4}$ In this case review, 2 patients were of pediatric age (cases A and I), and neither had any of the known risk factors associated with MRSA infections. Both patients had prior contact with a prisoner, prison facility, or athletic facility.

Antimicrobial sensitivity patterns are helpful when treating CA-MRSA infections because they can help the clinician choose the correct antibiotic. In the cases described above, 3 (30\%) showed resistance or intermediate resistance to the macrolides, whereas $6(60 \%)$ were sensitive (one was not recorded by the laboratory). The clinician needs to know that treatment of some clindamycin-susceptible CA-MRSA strains carrying the erm (erythromycin ribosome methylase) gene can be induced to become clindamycin-resistant during clindamycin treatment. ${ }^{15}$ The possibility for clindamycin resistance developing in a clindamycin-susceptible, erythromycin-resistant organism can be checked by the $\mathrm{D}$ test. This laboratory test is done by a doubledisk diffusion method in which the clindamycin zone becomes " $\mathrm{D}$ " shaped when a nearby erythromycin disk is used to induce the erm gene effect. In the United States, the prevalence of this inducible 
clindamycin-resistant strain seems to vary by geographic location. In Chicago and Minnesota, 94\% and $84 \%$ of CA-MRSA isolates, respectively, tested positive for inducible clindamycin resistance by the D test. In Houston, only $8 \%$ of all CA-MRSA isolates had a positive $\mathrm{D}$ test and thus were less likely to become clindamycin resistant. ${ }^{9}$

What then would lead the clinician to suspect a CA-MRSA infection? In this case review, several factors seemed common. First, the propensity for this infection to be misdiagnosed as either a spider bite or some type of skin or soft tissue infection (impetigo or furunculosis) based on appearance; second, the connection of CA-MRSA infections to correctional facilities-whether as a prisoner, a visitor, or someone having close contact with a former prisoner; third, the link to sports facilities; and fourth, the recurring nature of the infection. Thus, some clues to consider when dealing with a possible CA-MRSA skin or soft tissue infection are summarized below:

- Has the patient had any form of contact with a prisoner or prison facility?

- Has the patient or a close contact been treated for a "spider bite?"

- Has the patient experienced recurring skin infections such as "impetigo" or "furunculosis?"

- Does the patient play contact sports or have some other form of contact with a sports facility?

If a CA-MRSA infection is suspected, any abscess should be incised and drained and a microbiologic culture of wounds performed to determine appropriate antimicrobial agents. ${ }^{5}$ Swab specimens of the anterior nares could be obtained to check for carrier status ${ }^{6}$ if a patient has a history of recurring infections. If the patient is found to be a carrier of CA-MRSA, intranasal mupirocin may be considered, although the use of intranasal mupirocin is not advocated for use with every CA-MRSA infection because of the concern for future resistance. ${ }^{19}$ If a dermonecrotic lesion is identified, it is important to think not only of CA-MRSA but other infections as well-cutaneous anthrax, Lyme disease, cancerous lesions, and necrotizing fasciitis. A diagnosis of a brown recluse spider bite should be made after careful consideration is given to other possible diagnoses, especially if the patient is not within the region endemic to the brown recluse (southeastern Nebraska through Texas, east to Georgia and southernmost Ohio). ${ }^{16}$

Because transmission of CA-MRSA is primarily a problem with hygiene, it is important to instruct the patient and family on methods to prevent its spread. Patients should keep cuts and abrasions clean by washing with soap and water and to limit contact with common objects (eg, athletic equipment, towels, benches) and personal items (linen, pillows, clothing). ${ }^{5}$ Health care providers should use standard precautions to prevent transmission of MRSA infections in health care settings. ${ }^{20}$

\section{Conclusion}

In summary, it is probable that CA-MRSA infections are more common in the medical community and correctional facilities than clinicians are currently aware. At this time, the Centers for Disease Control and Prevention (CDC) are performing surveillance in several areas across the country to determine the prevalence and risk factors associated with this organism. A careful, thorough history will help identify those patients who may have had contact with CA-MRSA. Questions to ask the patient should include:

- Has the patient had contact with a correctional facility, prisoner or former prisoner?

- Have they or any of their close contacts been recently treated or told they had an infection from a spider bite?

- Have they been treated for recurring skin infections such as impetigo or furunculosis?

- Do they play any type of contact sports or work or work out at a gym or other sports facility?

These questions should help the clinician to quickly identify and properly treat infections caused by CA-MRSA. Ongoing studies by the CDC should provide more information on the recognition and treatment of this growing problem in health $_{\text {care. }}{ }^{21}$

Many thanks to Michael Parchman, MD, and Abraham Verghese, MD, for their time, advice, and help writing this article. Thanks also to Joe Babb and Methodist Health Care Ministries for their support of this article and for allowing time for research and writing. 


\section{References}

1. Groom AV, Wolsey DH, Naimi TS, et al. Community-acquired methicillin-resistant Staphylococcus aureus in a rural American Indian community. JAMA 2001;286:1201-5.

2. Herold BC, Immergluck LC, Maranan MC, et al. Community-acquired methicillin-resistant Staphylococcus aureus in children with no identified predisposing risk. JAMA 1998;279:593-8.

3. Purcell K, Fergie E. Exponential increase in community-acquired methicillin-resistant Staphylococcus aureus infections in south Texas children [letter]. Pediatr Infect Dis J 2002;21:988-9.

4. Lowy FD. Medical progress: Staphylococcus aureus infections. N Engl J Med 1998;339:520-32.

5. Outbreaks of community-associated methicillinresistant Staphylococcus aureus skin infections-Los Angeles County, California, 2002-2003. MMWR Morb Mortal Wkly Rep 2003;52:88.

6. Methicillin-resistant Staphylococcus aureus skin or soft tissue infections in a state prison-Mississippi, 2000. MMWR Morb Mortal Wkly Rep 2001;50:919-22.

7. Lindemayer JM, Schoenfeld S, O'Grady R, Carney JK. Methicillin-resistant Staphylococcus aureus in a high school wrestling team and the surrounding community. Arch Intern Med 1998;158:895-9.

8. Frank AL, Marcinak JF, Mangat PD, Tjhio JT, Kelkar S, Schreckenberger PC. Clindamycin treatment of methicillin-resistant Staphylococcus aureus infections in children. Pediatric Infect Dis J 2002;21: $530-4$.

9. Marcinak JF, Frank AL. Treatment of communityacquired methicillin-resistant Staphylococcus aureus in children. Curr Opin Infect Dis 2003;16:265-9.

10. Ma XX, Ito T, Tiensasitorn C, et al. Novel type of staphylococcal cassette chromosome mec identified in community-acquired methicillin-resistant Staphylococcus aureus strains. Antimicrob Agents Chemother 2002;46:1147-52.

11. Daum RS, Ito T, Hiramatsu K, et al. A novel methicillin-resistant cassette in community-acquired methicillin-resistant Staphylococcus aureus isolates of diverse genetic backgrounds. J Infect Dis 2002;186: $1344-7$.

12. Eady E, Cove JH. Staphylococcal resistance revisited: community-acquired methicillin-resistant Staphylococcus aureus-an emerging problem for the management of skin and soft tissue infections. Curr Opin Infect Dis 2003;16:103-24.

13. Fey PD, Said-Salim B, Rupp ME, et al. Comparative molecular analysis of community- or hospitalacquired methicillin-resistant Staphylococcus aureus. Antimicrob Agents Chemother 2003;47:196-203.

14. Bukharic HA, Abdelhadi MS, Saeed IA, Rubaish AM, Larbi EB. Emergence of methicillin-resistant Staphylococcus aureus as a community pathogen. Diag Micro Infect Dis 2001;40:1-4.

15. Osterhoudt KC, Zaoutis T, Zorc J. Lyme Disease masquerading as a Brown Recluse spider bite. Ann Emerg Med 2002;39:558-61.

16. Vetter RS, Bush SP. The diagnosis of brown recluse spider bite is overused for dermonecrotic wounds of uncertain etiology. Ann Emerg Med 2002;39:544-6.

17. Gross-Schulman S, Dassey D, Mascola L, Anaya C. Community-acquired methicillin-resistant Staphylococcus aureus [letter]. JAMA 1998;280:421-2.

18. Four pediatric deaths from community-acquired methicillin-resistant Staphylococcus aureus-Minnesota and North Dakota 1997-1999. MMWR Morb Mortal Wkly Rep 1999;48:707-10.

19. Hollis RJ, Barr JL, Doebbeling BN, Pfaller MA, Wenzel RP. Familial carriage of methicillin-resistant Staphylococcus aureus and subsequent infection in a premature neonate. Clin Infect Dis 1995;21:328-32.

20. CDC DHQP guidelines. MRSA-Information for healthcare personnel [updated 1999 Aug]. Available from: http://www.cdc.gov/ncidod/hip/aresist/ mrsahcw.htm

21. CDC DHQP information. Community-associated MRSA frequently asked questions [updated 2003 Aug]. Available from: http://www.cdc.gov/ncidod/ hip/aresist/mrsa_comm_faq.htm 